\title{
Achieving just transitions to low-carbon urban mobility
}

\author{
Energy and transportation researchers can contribute to the realization of just transitions to low-carbon mobility \\ in cities across the planet by elaborating and enacting broad conceptions of justice that consider distribution, \\ procedure, recognition and knowledge generation.
}

\section{Tim Schwanen}

O ptimism about the realization of rapid and large reductions in greenhouse gas (GHG) emissions from transportation is increasing, albeit only slightly and cautiously. Globally the third-largest source of such emissions ${ }^{1}$, the sector is extremely difficult to align with the Paris Agreement commitments. Nonetheless, the diffusion of electric mobility is accelerating worldwide, and the COVID19 lockdowns have demonstrated that dramatic changes in transportation can be achieved quickly, if the necessary political will emerges. Increasingly, governments, businesses and civil society are accepting that change must happen soon. This is why, at least in Europe, the phasing-out of internal combustion engines by national governments and the creation of low- or zero-emission zones in cities have become more popular.

The preoccupation with speed of change in policy settings - how to reduce GHG emissions from transportation and electrify motorized transport as quickly as possible - is understandable. However, too little consideration is given to justice in this context. Paying attention to justice in transition processes is both normatively appropriate and instrumentally important, if only to pre-empt resistance in certain population segments and accelerate change. If justice is considered, the focus is usually on distributive justice: who can or cannot adopt and benefit from low-carbon forms of mobility, and why. Distributive justice is vitally important, not least because electric vehicles (EVs) remain luxury goods ${ }^{2}$ and middle-income groups tend to benefit more from bus rapid transit (BRT) than the poor ${ }^{3}$.

Nevertheless, further dimensions of justice must be considered in relation to low-carbon mobility transitions. First, there is procedural justice, which concerns the nature of transition governance, including its inclusiveness and the influence involved or that affected constituencies can wield ${ }^{4}$. There is also recognition - respect for the rights, needs, values, understandings and customs of those affected by transition dynamics ${ }^{5}$ And there is epistemic justice, which has two components: the ability of affected constituencies to be heard and to offer their insights on whatever is at stake (testimonial justice), and the capacity of institutionalized knowledge-creation processes to adopt and respond appropriately to those insights (hermeneutical justice) ${ }^{6}$.

This broader understanding of justice can and should be foregrounded in research on low-carbon mobility transitions. This can be achieved through three propositions that are informed by literature on just energy transitions and on transport and mobility justice ${ }^{2,4,7,8}:$ (1) interdependent capabilities offer a useful indicator of distributive justice; (2) transformative governance approaches to urban mobility transitions should be developed; and (3) harnessing epistemic justice is critical to just transitions in urban mobility.

The discussion herein concentrates on mobility of people in cities because

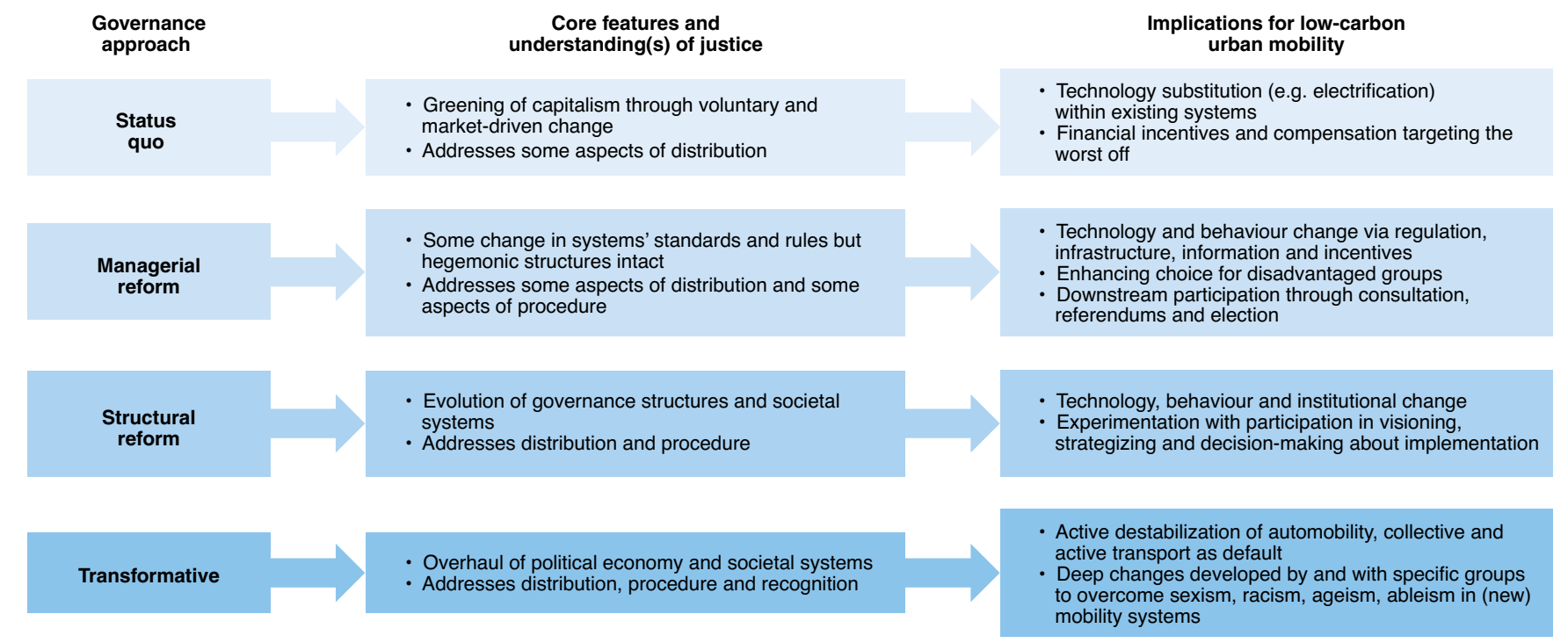

Fig. 1 | Four approaches to governing low-carbon transitions. These approaches were first identified by The Just Transition Research Collective ${ }^{12}$, and are extended here to urban mobility. 
movements by people outnumber freight movements and most of transportation's GHG emissions originate from urban areas where low-carbon mobility transitions also unfold most rapidly ${ }^{1}$.

\section{Proposition 1}

Distributive justice is crucial to low-carbon mobility transitions because access to and use of technologies such as EVs or bicycles and institutional arrangements such as Mobility-as-a-Service will likely remain socially and spatially unequal in urban areas. Yet a narrow focus on actual use is problematic because inequalities in revealed behaviour can result from choice, constraint or both. Concentrating on what people can or cannot do - their potential for action - circumvents thorny questions about how actual use should be interpreted, and prioritizes equality of opportunity over equality of outcome ${ }^{9}$.

Focusing on capabilities, as originally proposed by Amartya Sen ${ }^{10}$, is helpful in this context because it draws attention to the conditions and processes that make a given behaviour - a 'functioning' in Sen's vocabulary - effectively possible. Thus, to equitably reduce GHG emissions from urban mobility functionings, it is usually not enough to put in place a physical infrastructure such as a public network of EV charging installations, an integrated network of segregated bicycle lanes or a BRT system. The skills of using such infrastructures by people with different abilities, perceptions and (past) experiences also need to be considered. The same is true for discursive construction: an integrated cycling network may not translate into cycling functioning for many people if it is represented merely as enabling fast and reliable commuting to and from work or as an opportunity to enhance bodily fitness.

It is, however, critical to move beyond the individualistic perspectives on capabilities and functionings that dominate the transportation-related and wider literatures. Increasing capabilities in general is normally seen as desirable, but enhancing the capabilities enjoyed by person A or group X may diminish those of B or Y, who may be very close in space and time or affected 'at a distance'.

Proximity in space and time matters in various ways. For instance, the creation of a car-free city centre to enhance many people's capabilities to walk, cycle or use public transport may diminish the capabilities of people for whom driving a motorized vehicle is the only realistic possibility, for example, because of a disability. An example of consequences at a distance is the way in which interventions seeking to enhance capabilities to use EVs in a major city may, via many intermediate steps, diminish the capabilities of people having to cope with the urbanization pressures and pollution caused by intensified mining for lithium ${ }^{11}$.

Low-carbon mobility transitions thus entail a reconfiguring of the interdependencies of mobility-related and other capabilities across space and time. Foregrounding the interweaving of capabilities has significant policy relevance, not least because it can counteract libertarian objections that interventions like clean air zones or road pricing unduly restrict individual freedoms. Advocates can expose the myopia - and egoism of such arguments by drawing out how reduced numbers of (heavily polluting) vehicles on city streets can enhance non-car users' cycling capabilities on those very roads. Moreover, translation of such capabilities into observable cycling can generate imitation and safety in numbers. This in turn can generate socially inclusive, self-reinforcing trajectories of increasing cycling capabilities and functionings across wider segments of a city's population, including (former) car drivers.

This is where an interdisciplinary research agenda opens up. The stipulated dynamics can be evidenced by cross-disciplinary alliances, with engineers and computational scientists quantifying and simulating spatiotemporal dynamics in capabilities and functionings, based on empirical insights developed through in-depth research by social scientists and humanities scholars into how different capabilities are interrelated in practical situations. The simulations thus co-produced can do more than generate evidence-based policy. By drawing attention to indirect effects of interventions, they can also broaden the temporal horizon of policymaking processes.

\section{Proposition 2}

Considering procedure and recognition alongside distribution in research on low-carbon mobility transitions is easier if emphasis is placed on transition governance and what this seeks to achieve.

What the Just Transition Research Collective $^{12}$ calls status quo and managerial reform approaches (see Fig. 1) to transition governance prevail in transportation. Attempts to accelerate electrification efficiently and manage distributional inequalities are common under both these approaches.

Nonetheless, managerial reform approaches risk misrecognizing the rights, needs, values, understandings and/or customs of affected business and citizen communities. This is not least because the parameters to achieve procedural justice through participative processes are tightly constrained within managerial reform approaches. 'Downstream' participation when the terms of the debate have largely been decided by those in positions of authority - through consultation processes and voting tends to pre-empt radical change or genuine dissent, for instance with the deeply embedded assumption that enabling fast and efficient transport facilitates economic growth.

Status quo and managerial reform approaches to change in transportation reduce normative questions - what forms of movement to encourage, at the expense of what, and why - to technical ones like 'how best to.... This approach can unintentionally generate starkly politicized publics of concerned citizens, businesses, politicians and/or activists believing their voices remain unheard and their needs misrecognized ${ }^{13}$.

Beliefs of this kind constitute one reason why, in gentrifying urban neighbourhoods across North America, long-term residents challenge the rolling out of cycling infrastructures, which may enhance the risk of their displacement by further increasing property values $^{14}$. This is also why drivers of semi-legal and illegal minibus taxis across large parts of Africa resist the creation of BRT systems that may displace them from their most lucrative routes ${ }^{15}$.

In cities worldwide, cycling activism exemplifies transformative governance (Fig. 1). It cultivates not only cycling-related capabilities without compromising others, but also procedural justice and recognition ${ }^{16}$. Yet, cycling activists' attentiveness to the specific needs (recognition) of particular groups - for example, disadvantaged youth or disabled people - and tailored governance arrangements (procedure) have yet to scale to the levels of whole city or country populations. It is unclear if and how cycling activism offers useful templates for the governing of whole-system transitions to low-carbon mobility.

This opens up another interdisciplinary research agenda requiring inputs from engineering, critical social science, humanities, technology design studies and other fields: how governance arrangements can cultivate genuinely transformative change in urban mobility. Recent experimentation with citizen assemblies ${ }^{17}$ on the British Isles and with transition management ${ }^{18}$ across Europe and elsewhere can usefully inform that agenda, and so can longer-standing work on polyrational ('clumsy') approaches to the governance of change $^{19}$. Yet, further experimentation and creativity in thinking and practice will be required, and across the planet. 


\section{Proposition 3}

Finally, a focus on distribution, procedure and recognition should also be complemented by due regard for epistemic justice in research and governance. This is because transportation and energy researchers contributing to low-carbon mobility transitions should not assume a priori that their understanding of the capabilities, behaviours, interests and values of individuals and constituencies affected by those transitions are robust and sufficiently sensitive to time, place and social position. Those understandings are ultimately partial and shaped by researchers' personal biographies, (inter)disciplinary histories and customs, and the traditional valorization of universal and objective knowledge over contextual, place-specific and socially situated knowledges.

As one leg of epistemic justice ${ }^{6}$, the ability of communities affected by low-carbon mobility transitions to articulate their understandings and experiences testimonial justice - demands resolute methodological pluralism from energy and transportation researchers. Storytelling, participatory mapping, methods for capturing sound or haptic knowledge, video ethnography, and other underutilized approaches should all be deployed, on their own and together with quantitative methods, so as to foreground the knowledge of as many constituencies in the city as possible, including its most marginalized residents.

This in turn demands critical reflection on the hermeneutical questions of what can constitute (scientific) evidence and how marginalized perspectives and experiences can be examined, articulated and mobilized in responsible and non-exploitative ways. Energy and transportation researchers can learn much from often decades-long debates on these questions in feminist, queer, disability, Black and post- and decolonial studies ${ }^{20,21}$.

Considering hermeneutical justice is the bigger challenge because it involves confronting the path dependencies in how energy and transportation researchers understand the processes they study. What, for instance, is left out by studying urban mobility with the help of systems theories and/or as the outcome of decision-making by (boundedly) rational individuals? And when responding to experiences of change in urban mobility from the social and geographical margins, can researchers remain content to ground their thinking about technology, behaviour and institutions in the Euro-white theories and world views they have relied on all along? Addressing hermeneutical justice in the context of low-carbon mobility transitions can be an unsettling experience to which not all protagonists and stakeholders will want to commit.

Energy and transportation academics, and particularly those with social science and humanities backgrounds, have a unique responsibility to harness epistemic justice in low-carbon mobility transitions. They should, however, refrain from simply imposing their own beliefs and definitions of what constitutes (epistemically) just transition pathways on other constituencies in those processes. Nor should they merely criticize or deconstruct others' habitual thinking about technology, behaviour and institutions. As philosopher of science Isabelle Stengers ${ }^{22}$ proposes, their responsibility consists of cultivating among the involved and affected communities the capability to assess innovations like new mobility technologies, practices and/or institutional arrangements in participatory processes, instead of judging those innovations based on a priori values and beliefs.

On the one hand, this involves making constituencies such as local politicians, policymakers, entrepreneurs, vocal citizen groups and seasoned activists aware of the particularity of their knowledge and thought styles. On the other, this entails fostering and staging encounters with otherwise marginalized views and experiences for those constituencies within and through research activities. The combined result may be the emergence of different and more differentiated understandings of what effects mobility innovations generate and how those innovations and transition pathways might be governed in a given city.

This approach can be particularly beneficial when controversies and concerned publics arise during low-carbon mobility transitions, as often happens with urban interventions that diminish capabilities to drive fossil-fuel-powered private vehicles. It can also puncture locally prevailing discourses and atmospheres promulgated by vocal collectives of businesses, activists, citizens and/or policymakers supporting or resisting the interventions. This in turn can create room for reticent, marginalized views and concerns, and nurture novel and different capacities to envisage, imagine, think, govern and realize low-carbon mobility futures in a city.

\section{Conclusion}

What constitutes a just transition to low-carbon urban mobility cannot be defined in the abstract or a priori. This needs to be developed collectively, in practice and for each particular urban context. Researchers can contribute to the realization of just transitions in a particular place by studying interdependent capabilities, enabling involved and affected constituencies to participate in governance and knowledge generation, and creating conditions that enable marginalized perspectives and experiences to shift transition pathways towards low-carbon mobility in previously unimaginable directions.

\section{Tim Schwanen (D)}

Transport Studies Unit, School of Geography and the Environment, University of Oxford, Oxford, UK.

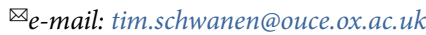

Published online: 7 June 2021

https://doi.org/10.1038/s41560-021-00856-Z

References

1. Sims, R. et al. in Climate Change 2014: Mitigation of Climate Change (eds Edenhofer, O. et al.) 599-670 (IPCC, Cambridge University Press, 2014).

2. Sovacool, B. K., Kester, J., Noel, L. \& Zarazuade Rubens, G. Energy injustice and Nordic electric mobility: inequality, elitism, and externalities in the electrification of vehicle-to-grid (V2G) transport. Ecol. Econ. 157, 205-217 (2019).

3. Venter, C., Jennings, G., Hidalgo, D. \& Valderrama Pineda, A. F. The equity impacts of bus rapid transit: a review of the evidence and implications for sustainable transport. Int. J. Sustain. Transp. 18, 140-152 (2018).

4. Williams, S. \& Doyon, A. Justice in energy transitions. Environ. Innov. Soc. Transit. 31, 144-153 (2019).

5. Fraser, N. Social Justice in the Age of Identity Politics: Redistribution, Recognition, and Participation (Stanford University, 1998).

6. Fricker, M. Epistemic Injustice: Power and the Ethics of Knowing (Oxford University Press, 2007).

7. Sheller, M. Mobility Justice: The Politics of Movement in an Age of Extremes (Verso, 2018)

8. Verlinghieri, E. \& Schwanen, T. Transport and mobility justice: evolving discussions. J. Transp. Geogr. 87, 102798 (2020).

9. Robeyns, I. Wellbeing, Freedom and Social Justice: The Capability Approach Re-examined (Open Book Publishers, 2017)

10. Sen, A. Commodities and Capabilities (North-Holland, 1985).

11. Henderson, J. EVs are not the answer: a mobility justice critique of electric vehicle transitions. Ann. Am. Assoc. Geogr. 110, 1993-2010 (2020).

12. The Just Transition Research Collective. Mapping Just Transition(s) to a Low-Carbon World (UNRISD, 2018).

13. Dewey, J. The Public and Its Problems: An Essay in Political Enquiry (Henry Holt and Company, 1927).

14. Stehlin, J. Cyclescapes of the Unequal City: Bicycle Infrastructure and Uneven Development (University of Minnesota Press, 2019).

15. Rizzo, M. Taken For a Ride: Grounding Neoliberalism, Precarious Labour, and Public Transport in an African Metropolis (University of Oxford Press, 2017)

16. Schwanen, T. Low-carbon mobility in London: a just transition? One Earth 2, 132-134 (2020).

17. Devaney, C., Torney, D., Brereton, P. \& Coleman, M. Ireland's citizens' assembly on climate change: lessons for deliberative public engagement and communication. Environ. Commun. 14, 141-146 (2020)

18. Bosman, R., Loorbach, D., Rotmans, J. \& Van Raak, R. Carbon lock-out: leading the fossil port of Rotterdam into transition. Sustainability 10, 2558 (2018).

19. Ney, S. \& Verweij, M. Messy institutions for wicked problems: How to generate clumsy solutions? Environ. Plann. C Politics Space 33, 1679-1696 (2015).

20. Smith, L. T. Decolonizing Methodologies: Research and Indigenous Peoples (Zed Books, 2012).

21. Browne, K. \& Nash, C. J. (eds) Queer Methods and Methodologies: Intersecting Queer Theories and Social Science Research (Routledge, 2016).

22. Stengers, I. Another Science is Possible: A Manifesto for Slow Science (Polity Press, 2018).

Acknowledgements

The ideas condensed in this manuscript were made possible by ESRC grants ES/N011538/1 and ES/W000539/1.

Competing interests

The author declares no competing interests. 